\title{
Programa de intervenção em contexto educativo: dispositivo electrónico de avaliação da descodificação fonética de aprendentes de Português Língua Segunda
}

\author{
Sandra Figueiredo \& Carlos Fernandes da Silva \\ Universidade de Aveiro, Portugal
}

\begin{abstract}
Resumo
O comportamento verbal concretiza-se porque, por um lado, existe um sistema de princípios e condições que, por si só, são considerados os elementos universais inerentes a todas as línguas naturais, determinados pela necessidade biológica, mas, por outro lado, esses elementos integram uma relação dinâmica de eventos que constituem o contexto do sujeito. Neste contexto, esses eventos não são apenas as estruturas cerebrais (perspectiva mentalista), mas todos os elementos que geram um conjunto de estímulos a ser discriminados e que apelidamos de 'meio ambiente' (perspectiva funcional). Após uma breve revisão teórica de conceitos e abordagem de processos de descodificação fonética, serão apresentados resultados decorrentes da aplicação da bateria de testes (instrumento da pesquisa). Será ainda orientada uma discussão especificamente sobre o desempenho de sujeitos aprendentes de Português Língua Segunda (amostra do estudo) relativamente aos testes de segmentação de palavras (soletração) e de identificação de pares mínimos.
\end{abstract}

Palavras-chave

Intervenção educativa; Instrumento de avaliação; Percepção fonética; Língua Segunda

\section{Introdução}

O sujeito criança, no desenvolvimento da sua faculdade de linguagem, alterna entre comportamentos com base na imitação e comportamentos com 
base na operação autónoma de desvios - desempenho emergente e generalização (Skinner, 1978). Este processo é inconscientemente controlado pelas práticas (operantes verbais) da comunidade linguística do sujeito, que determinam a sua aprendizagem. O ser humano nas primeiras semanas de vida começa a ensaiar sons: os primeiros são meramente biológicos (fase pré-fonemática), que posteriormente são substituídos pela emissão de sons próximos da fonética do seu meio linguístico (Jusczyk, 1994). Contudo, os sons da língua não são mais difíceis do que os biológicos, ambos os tipos exigindo esforço de apropriação da criança face ao meio em que se insere, no qual ambas as fontes de estímulos se encontram.

O sujeito, ao desenvolver linguagem, desenvolve conhecimento que, por si só, é social (o comportamento é sempre uma operação social); logo, o ser humano, desde que começa a discriminar sons da fala, está a iniciar o desenvolvimento da "linguagem socializada". A gramática que o sujeito adquire gradualmente é um instrumento de verbalização das suas intenções de comunicação, bem como reflecte a sua projecção, pois as categorias gramaticais não existem na natureza (Postman \& Weingartner, 1971), são convenções do Homem e que apenas têm significado na relação que individualmente estabelecemos com os referentes pretendidos. O significado aprendido dos conceitos varia de acordo com o contexto em que um mesmo conceito é aplicado, daí que o condicionamento operado pelas comunidades verbais é parcial, na medida em que os significados da linguagem variam de acordo com a percepção do indivíduo - o sistema de símbolos (representado numa Língua) é, na verdade, um ponto de vista (Postman \& Weingartner, 1971).

Para os processos de codificação e descodificação linguística, os padrões de activação neuronal no cérebro estão em constante 'fluxo perceptual', sendo que a assimilação de nova informação fonética implica a acomodação e reestruturação ao nível essencialmente neuronal, no decurso da aprendizagem. Esse fluxo pode ser mais fortemente activado quando determinados desafios se colocam (como, por exemplo, o efeito das palavras homófonas), sendo que a percepção se torna mais refinada com o conhecimento da pronúncia e da sua ortografia. Assim, quanto maior é a frequência de léxico, mais eficiente se torna a activação porque é interiorizado o esquema de identificação pelas vias ortográfica e fonológica (ver Gillon, 
2004). Por outro lado, teremos de considerar que a percepção dos segmentos sonoros tem uma base neurológica, isto é, são criados traços específicos fonéticos, associados a uma determinada representação neuronal (no córtex auditivo do hemisfério esquerdo, em princípio), desenvolvidos nos primeiros tempos de vida, no contexto de aquisição de linguagem materna (Lenneberg, 1967). Essa representação poderá ser acrescentada/alterada em contexto de nova aprendizagem linguística.

A percepção do discurso, enquanto apenas conjunto de traços fonéticos que, por sua vez, constituem o reconhecimento precoce do princípio da propriedade definidora de código linguístico, varia ao longo do primeiro ano de vida do ser humano (início mais evidente aos quatro meses de vida); contudo é pelos doze meses que as crianças já discriminam os sons de dois sistemas, quando se encontram expostas a um sistema bilingue (Bosch \& Sebastián-Gallés, 2003). Ainda que na fase de consciência em formação, percebem dois sistemas fonéticos e fonológicos, sendo que a discriminação visual é predominante (a criança imita predominantemente os movimentos orofaciais dos outros) e começa a ser fácil distinguir, pelos movimentos faciais dos interlocutores, qual a língua que está a ser emitida. Quanto à produção, esta competência vai sendo desenvolvida sobretudo até aos quatro anos de idade - ensaio fonético articulatório.

No caso dos monolingues, a percepção do discurso é conseguida durante a primeira metade do primeiro ano de vida, sendo que reagem face aos sons familiares e não familiares, captando mais eficazmente os traços fonéticos salientes quanto à evidência das suas propriedades (Jusczyk \& Bertoncini, 1988). Contudo, durante a segunda metade do primeiro ano, essa capacidade entra em "latência", indicando um declínio natural no processo, cuja capacidade é recuperada aos 12 meses (Floccia, Nazzi, Austin, Arreckx, \& Goslin, 2010). No caso dos sujeitos bilingues, esse processo é menos linear, na medida em que ocorrem mais fases de declínio e recuperação na competência discriminatória, contribuindo para o aperfeiçoamento da mesma relativamente aos dois sistemas fonéticos.

Pelos 17 meses (fase da emergência fonemática), o ser humano possui a informação fonética para a discriminação em contexto, mas ainda não sabe usar o comportamento, porque ainda não se identificam suficientes detalhes fonéticos para justificar o processo discriminatório (Bruck \& Genesee, 1995). Com a entrada na etapa fonemática, a compreensão do 
léxico passa a ter sentido (descodificação e codificação) fonológico, e não apenas fonético. A atenção da criança bilingue é maior relativamente à assimilação de novo léxico; contudo, demora mais tempo na decisão lexical, pois envolve maior selecção e 'consulta' das categorias fonéticas que conhece. A performance dos bilingues poderá estar mais implicada neste momento do processo de descodificação, em relação aos monolingues, mas desenvolvem mais rapidamente a consciência metafonológica.

Um importante factor na explicação do processo de descodificação de fones e fonemas em contexto de Língua Segunda (L2) ou Estrangeira (LE) reside no tipo de ortografia materna do indivíduo. A noção da unidade mínima (fonema) ou maior (sílaba) varia enquanto forte ou fraco preditor nas competências de descodificação de escrita e leitura, sendo que os sujeitos que dominam línguas com ortografias consistentes (e transparentes) línguas que apresentam um código ortográfico e fonológico com mais correspondência entre si do que noutros casos de idiomas em que a correspondência entre grafema e fonema é quase ausente (línguas opacas) - beneficiam do conhecimento das unidades mínimas, ao passo que os indivíduos com ortografias maternas mais inconsistentes (opacas) beneficiam da consciência das unidades maiores (Ziegler, Jacobs, \& Braun, 2001). Os mesmos itens, em linguagem verbal, podem ser, assim, processados de forma diferente para atingir o mesmo sucesso. Este tipo de diferenças ortográficas e, portanto, alfabéticas, constitui a contingência que determina o plano das relações entre os componentes (o estímulo que se concretiza no enunciado verbal em L2, a acção do sujeito, a resposta e consequência pode ser positiva ou negativa de acordo com o resultado esperado após processamento de uma mensagem linguística) cuja acção dinâmica define o comportamento.

O mesmo alfabeto pode ser diferente para duas línguas ou duas línguas podem exibir diferentes alfabetos (o que determina maior incidência de erro na transferência entre línguas). Contudo, línguas com o mesmo tipo de alfabeto contêm na sua matriz fonológica unidades mínimas diferentes em natureza articulatória (as características articulatórias como critério de categorização) e em número. O aprendente de L2, ao aprender a nova matriz fonológica, aplica sempre a sua versão idiossincrática e formula uma matriz fonológica com variantes livres (uma variação que depende do próprio locutor e não do contexto fonológico) que, por sua vez, caracterizam o seu sotaque (Schütz, 2005). 
Diferentes sistemas de escrita representam unidades diferentes de significação (sílabas, fonemas ou morfemas) e exibem diferentes propriedades. A aprendizagem de L2 implica novos conhecimentos das unidades linguísticas, novas regras, convenções ortográficas, e mesmo novas adequações ao nível de movimentos manuais e oculares. Assim, o sujeito aprendente de L2 encontra-se a mudar para "biliterate and biscriptal" (Bassetti, 2005, p. 1), com aquisição de nova consciência fonémica e grafológica.

Este tipo de diferenças enunciadas, quer internas (estruturas neurobiológicas inatas e em maturação) ou externas (o exemplo dos alfabetos e diferentes sistemas fonológicos), explica os processos de mudança, no seio do desenvolvimento, e de aquisição de novos conhecimentos, essencialmente fonológicos e ortográficos. No entanto, esses processos necessitam de uma observação e descrição rigorosas que só é possível com uma avaliação científica organizada. Este estudo vai ao encontro desta necessidade, centrando a sua metodologia na análise e explicação de desempenhos e comportamentos de aprendentes de Português (Europeu) como Língua Segunda, em níveis e contextos particulares de língua.

\section{Metodologia}

O presente estudo insere-se no contexto de uma investigação que se organizou em duas importantes fases de avaliação de comportamentos dos sujeitos em condição de aprendizagem de L2: motivação (i) e desempenho (ii). No que respeita ao segundo ponto, foi desenvolvida uma bateria de 12 testes em formato electrónico, com o objectivo de avaliação de níveis específicos de língua: silábico, intrassilábico e fonémico, observando o desempenho de indivíduos com experiência migratória em diferentes tarefas. Os dados auto-reportados e o tempo despendido em cada teste foram registados numa base de dados categorizada de acordo com as variáveis (o perfil de cada teste da bateria) definidas para o estudo.

\section{Participantes}

Amostra dos casos: 61 sujeitos (aprendentes de Português L2, com experiência migratória) com uma média de idades de 16,1 e desvio-padrão de 
6,3, sendo que 19 (31,1\%) são crianças (idades entre 7 e 12 anos), 22 $(36,1 \%)$ são adolescentes (idades compreendidas entre os 13 e os 18 anos) e 20 (32,8\%) são adultos (idades entre 19 e 30 anos), que se encontram distribuídos pelos níveis do Ensino Básico, Secundário e Superior. Os participantes deste estudo apresentam, no total, cerca de 26 nacionalidades distintas (ver figura 1: 31 nacionalidades reportadas na fase I do estudo de Doutoramento; na fase II, encontramos a amostra reduzida e 26 nacionalidades, após selecção para a aplicação da bateria de testes), sendo que a variedade de nacionalidades, bem como de línguas faladas, é intencional - não pretendemos especificar grupos de nacionalidades ou de locutores, como perspectiva habitual de estudos nesta área.

A heterogeneidade da amostra é um critério explicado pelo objectivo geral do estudo de avaliar as efectivas diferenças dos aprendentes de acordo com os seus perfis, essencialmente visando a observação da predisposição cognitiva ao longo dos diferentes grupos de idades, percebendo os graus de dificuldades hipoteticamente decorrentes da interferência de específicas línguas maternas dos aprendentes e avaliando o impacto da experiência migratória (data de chegada a Portugal) na performance reportada.

Ainda, a selecção de toda a amostra pautou-se por dois importantes parâmetros, enquanto definidores específicos da experiência migratória pretendida: data de chegada a Portugal e nível de proficiência no Português. A indicação da proficiência de cada elemento da amostra baseou-se nas avaliações diagnósticas específicas levadas a cabo pelos próprios estabelecimentos de ensino. Os níveis de proficiência visados para este estudo são A2 e B1 (Comissão Europeia, 2001). Não foi considerado o nível A1, pois o aluno não poderia compreender as questões colocadas na bateria de testes. Destacamos o facto de serem estes os níveis (incluindo o A1) considerados para o requisito de apoio ao Português Língua não Materna, visados nos documentos orientadores (Leiria, 1999; Ministério da Educação, 2005) e na legislação para a aplicação de medidas curriculares, nas escolas respectivas. Por outro lado, foram considerados os sujeitos que tivessem chegado a Portugal pela primeira vez, sem anteriores conhecimentos do Português, há não mais de quatro anos, com relevância para a data de 2006.

Constatámos que, no que respeita especificamente à amostra, existem cerca de vinte e duas línguas, no total, em que os sujeitos são locutores 
activos. No que respeita a apoio que recebem no âmbito da disciplina de Português, $42(68,9 \%)$ encontram-se em programas de apoio ao Português enquanto disciplina curricular, sobretudo. Este tipo de apoio encontra-se em fase de iniciação, na medida em que os alunos não chegaram, em grande parte, há mais de um ano. Os restantes $19(31,1 \%)$ não recebem qualquer apoio (os que se encontram há mais tempo em Portugal).

Figura 1 - Identificação dos países de origem e das línguas maternas da amostra portuguesa

\begin{tabular}{llll}
\hline País de origem & & Línguas faladas & em casa \\
\hline Roménia & Cazaquistão & Espanhol & Chinês \\
Índia & Itália & Crioulos & Romeno \\
França & Hungria & Inglês & Português \\
Marrocos & Angola & Letão & Ucraniano \\
Venezuela & Bielorrússia & Cazaque & Hindi \\
Letónia & Congo & Kimbundo & Alemão \\
Cabo-Verde & Colômbia & Italiano & Bangla/Bengali \\
São-Tomé e & Coreia & Francês & Umbundo \\
Príncipe & E.U.A. & & Húngaro \\
Suíça & Moçambique & & Búlgaro \\
Portugal & México & & \\
Rússia & Bulgária & & \\
Alemanha & Luxemburgo & & \\
Brasil & República & & \\
China & Dominicana & & \\
Ucrânia & Guiné-Bissau & & \\
Inglaterra & & & \\
\hline
\end{tabular}

Amostra Imigrante Portuguesa

\section{Instrumentos}

Bateria de testes de avaliação de comportamentos verbais em contexto de Língua Segunda: o objectivo desta bateria de doze testes, preparada como instrumento de investigação, consiste essencialmente na avaliação de diversos níveis da consciência fonológica (silábico, intrassilábico e fonémico) no contexto do idioma Português (Língua Segunda). A bateria foi desenvolvida pelos autores do presente estudo, em forma original e reunindo características de provas utilizadas em determinadas avaliações de 
comportamentos verbais. Foi decidido o suporte electrónico com o objectivo de garantir maior efectividade, validade e organização dos dados, bem como para apresentar estruturadamente as tarefas em estilo dinâmico e atractivo.

O teste apresenta simultaneamente a folha de respostas, de resultados e de cotações, com um manual em suporte papel. A sua disponibilização será feita on-line com divulgação prévia das normas de acesso e utilização. Todos os dados (respostas dos sujeitos e tempo despendido, contabilizado em segundos, em cada teste) encontram-se registados seguramente na base de dados construída para o efeito. Foi elaborada uma versão em inglês do mesmo teste. $\mathrm{O}$ trabalho de programação do teste (em Active Server Pages, dependente da instalação do servidor Internet Information Server, num único computador portátil) decorreu entre Outubro de 2006 e Janeiro de 2007. Esta bateria, no contexto de aplicação à amostra dos casos, revela boa consistência interna com alfa de Cronbach de .75 ( $\mathrm{N}$ de itens=52).

Os dados aqui reportados referem-se apenas a dois testes seleccionados para discussão: o teste de soletração (segmentação dos fones de quatro palavras e, em actividade invertida, o registo escrito de palavras soletradas) e o teste de identificação de pares mínimos (dois pares mínimos com diferentes estruturas fonémicas). Os estímulos apresentados em cada teste (as palavras testadas) encontram-se informados nas imagens das tarefas apresentadas na secção "resultados". A segmentação foi solicitada em registo oral, sendo que a identificação dos pares mínimos implicou o registo escrito. Todos os dados foram automaticamente registados na base de dados. A audição dos segmentos e o registo oral das respostas são assegurados com base nos dispositivos básicos que o software apresenta para exibição e gravação de informação áudio. O registo das respostas escritas depende da submissão que cada sujeito tem de fazer após a realização de cada tarefa (todos os testes exibiam um comando "submeter"; deste modo, as respostas eram guardadas na base de dados inerente à bateria).

Os testes aqui enunciados dirigem-se à avaliação do conhecimento fonológico, mas também ortográfico, sobretudo na tarefa de identificação dos pares mínimos, em que têm de aplicar o código escrito para indicar as palavras ouvidas previamente. 


\section{Procedimentos}

Cumprida a fase do estudo exploratório, o teste foi aplicado aos alunos nas suas próprias escolas, num computador portátil preparado para o efeito, sendo que o preenchimento do teste demorou cerca de 50 minutos. Este processo, que seguiu várias etapas (pedido de autorização, levantamento de dados pelos estabelecimentos, selecção dos sujeitos, formalização dos consentimentos, recepção dos consentimentos e autorização por parte da entidade), foi iniciado em Setembro de 2006, de modo que a aplicação da bateria, por sua vez, teve início em Janeiro de 2007 (término: Dezembro de 2007).

Os sujeitos mais jovens foram mais auxiliados na compreensão dos enunciados propostos em cada teste. A investigadora leu e explicou todas as questões aos aprendentes com menos de 12 anos de idade. Além do suporte oral, os cenários das questões da bateria encontram-se numa linguagem visivelmente facilitada e preparada para não comprometer a execução das tarefas (por exemplo, não se recorre, no enunciado da tarefa de soletração/segmentação, a "soletra", mas sim a "diz letra e letra").

\section{Análise dos dados}

Para este estudo, determinámos a avaliação do desempenho com base nos testes de análise de distribuição (Qui-Quadrado). Para o efeito, recorremos ao programa SPSS 15.0.

\section{Resultados}

Antes da descrição dos resultados, pretende-se legendar as variáveis independentes e dependentes (nomeadamente, os testes que serão reportados), de forma a compreender a interacção de factores observados no presente estudo. É ainda apresentado um printscreen do layout dos testes tais como se encontram na bateria quando activada na devida plataforma, por meio dos códigos de acesso.

*Variáveis independentes

"Classe Etária" (Grupo I: 7-12 anos; Grupo II: 13-18 anos; Grupo III: 1930 anos).

*Variáveis dependentes (testes da bateria) 
(Teste 3) "Identificação de pares mínimos" (resposta correcta: identificação de dois pares mínimos ouvidos, através do registo da letra diferenciadora em cada par);

(Teste 4) "Soletração" (a. segmentação) e "Leitura 1" (resposta correcta: soletração e leitura integral de quatro palavras); "Reconstrução fonémica" (b.) (resposta correcta: síntese fonémica de três palavras ouvidas).

I.

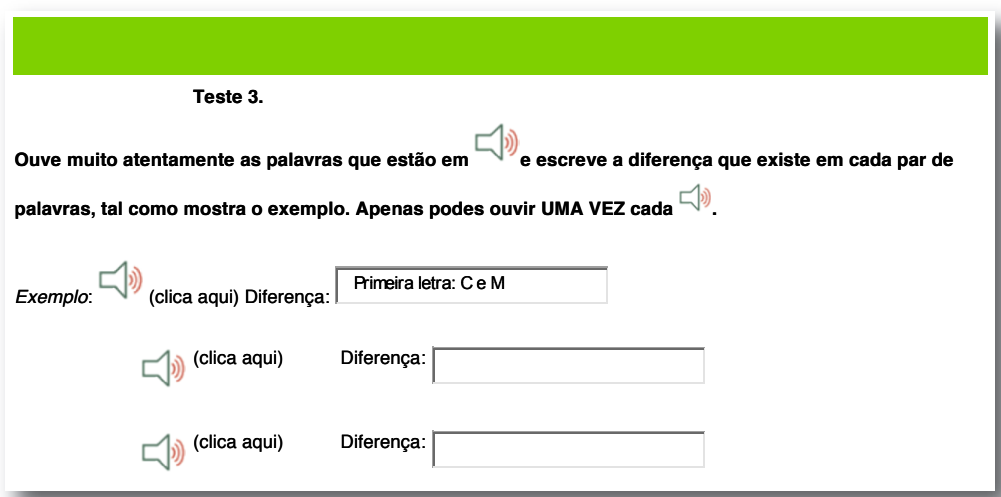

Relativamente à distribuição dos participantes em função das variáveis "Classe etária" e "Identificação de pares mínimos" (teste 3), verifica-se que a distribuição não se deve ao acaso ( $\chi 2=20.728$; g.I._10; p_.023; $\eta=.470)$. Nas diferenças para a variável "Identificação de Pares mínimos" entre as categorias de "Classe etária", é o grupo V que apresenta mais acertos (27,3\% - 2 registos), seguindo-se o grupo III (25,9\% - 1 registo). O grupo que menos acerta é o grupo I (38,1\%). Observe-se a tabela 1. 
Tabela 1 - Distribuição dos grupos etários de acordo com o seu desempenho no teste de Identificação de pares mínimos (teste 3) e grupos etários

\begin{tabular}{|c|c|c|c|c|c|c|}
\hline & & & \multicolumn{3}{|c|}{$\begin{array}{c}\text { Teste de identificação de } \\
\text { pares mínimos ( }{ }^{\circ} \text { de } \\
\text { registos) }\end{array}$} & \multirow[t]{2}{*}{ Total } \\
\hline & & & 0 & 1 & 2 & \\
\hline \multirow{28}{*}{$\begin{array}{l}\text { Grupos } \\
\text { etários }\end{array}$} & $7-9$ & $\mathrm{~N}$ & 8 & 0 & 1 & 9 \\
\hline & & $\%$ nos grupos determinados por idade & $88,9 \%$ &, $0 \%$ & $11,1 \%$ & $100,0 \%$ \\
\hline & & $\begin{array}{l}\% \text { no teste de identificação de pares } \\
\text { mínimos }\end{array}$ & $38,1 \%$ &, $0 \%$ & $9,1 \%$ & $15,3 \%$ \\
\hline & & $\%$ Total & $13,6 \%$ &, $0 \%$ & $1,7 \%$ & $15,3 \%$ \\
\hline & $10-12$ & $\mathrm{~N}$ & 3 & 4 & 2 & 9 \\
\hline & & $\%$ nos grupos determinados por idade & $33,3 \%$ & $44,4 \%$ & $22,2 \%$ & $100,0 \%$ \\
\hline & & $\begin{array}{l}\text { \% no teste de identificação de pares } \\
\text { mínimos }\end{array}$ & $14,3 \%$ & $14,8 \%$ & $18,2 \%$ & $15,3 \%$ \\
\hline & & $\%$ Total & $5,1 \%$ & $6,8 \%$ & $3,4 \%$ & $15,3 \%$ \\
\hline & 13-15 & $\mathrm{N}$ & 7 & 7 & 1 & 15 \\
\hline & & $\%$ nos grupos determinados por idade & $46,7 \%$ & $46,7 \%$ & $6,7 \%$ & $100,0 \%$ \\
\hline & & $\begin{array}{l}\text { \% no teste de identificação de pares } \\
\text { mínimos }\end{array}$ & $33,3 \%$ & $25,9 \%$ & $9,1 \%$ & $25,4 \%$ \\
\hline & & $\%$ Total & $11,9 \%$ & $11,9 \%$ & $1,7 \%$ & $25,4 \%$ \\
\hline & $16-18$ & $\mathrm{~N}$ & 0 & 4 & 2 & 6 \\
\hline & & $\%$ nos grupos determinados por idade &, $0 \%$ & $66,7 \%$ & $33,3 \%$ & $100,0 \%$ \\
\hline & & $\begin{array}{l}\text { \% no teste de identificação de pares } \\
\text { mínimos }\end{array}$ &, $0 \%$ & $14,8 \%$ & $18,2 \%$ & $10,2 \%$ \\
\hline & & $\%$ Total &, $0 \%$ & $6,8 \%$ & $3,4 \%$ & $10,2 \%$ \\
\hline & $19-23$ & $\mathrm{~N}$ & 2 & 6 & 3 & 11 \\
\hline & & $\%$ nos grupos determinados por idade & $18,2 \%$ & $54,5 \%$ & $27,3 \%$ & $100,0 \%$ \\
\hline & & $\begin{array}{l}\text { \% no teste de identificação de pares } \\
\text { mínimos }\end{array}$ & $9,5 \%$ & $22,2 \%$ & $27,3 \%$ & $18,6 \%$ \\
\hline & & $\%$ Total & $3,4 \%$ & $10,2 \%$ & $5,1 \%$ & $18,6 \%$ \\
\hline & 24-30 & $\mathrm{N}$ & 1 & 6 & 2 & 9 \\
\hline & & $\%$ nos grupos determinados por idade & $11,1 \%$ & $66,7 \%$ & $22,2 \%$ & $100,0 \%$ \\
\hline & & $\begin{array}{l}\% \text { no teste de identificação de pares } \\
\text { mínimos }\end{array}$ & $4,8 \%$ & $22,2 \%$ & $18,2 \%$ & $15,3 \%$ \\
\hline & & $\%$ Total & $1,7 \%$ & $10,2 \%$ & $3,4 \%$ & $15,3 \%$ \\
\hline & Total & $\mathrm{N}$ & 21 & 27 & 11 & 59 \\
\hline & & $\%$ nos grupos determinados por idade & $35,6 \%$ & $45,8 \%$ & $18,6 \%$ & $100,0 \%$ \\
\hline & & $\begin{array}{l}\text { \% no teste de identificação de pares } \\
\text { mínimos }\end{array}$ & $100,0 \%$ & $100,0 \%$ & $100,0 \%$ & $100,0 \%$ \\
\hline & & $\%$ Total & $35,6 \%$ & $45,8 \%$ & $18,6 \%$ & $100,0 \%$ \\
\hline
\end{tabular}


II

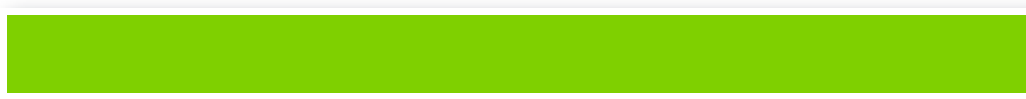

Teste 4. (gravação áudio)

a) Diz letra a letra as seguintes palavras, tal como mostra o exemplo.

Exemplo: 5 s)) (clica aqui para ouvires o exemplo)
a) passagem
b) bagagem

c) vaso

d) onda

b) Ouvindo com atenção, descobre e escreve as palavras que estão soletradas (ditas letra a letra) em cada (fil):

a)

b)

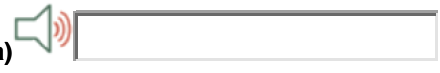<smiles>C1=CC2CCC1C2</smiles>

c)

Quanto à distribuição dos participantes em função das variáveis "Classe etária" (considerando 3 grupos) e "Segmentação" (tarefa 4a), verificase que, para ambas, a distribuição não se deve ao acaso ( $\chi 2=7,039 ;$ g.2_10; p_.030; $\eta=.263)$. Nas diferenças para a variável "Segmentação" entre as categorias de "Classe etária", é o grupo II (13-18 anos) que apresenta uma segmentação oral e leitura mais bem-sucedidas (53,3\%), sendo o grupo III o que exibe uma leitura menos positiva $(43,8 \%)$. Observe-se a tabela 2. 
Tabela 2 - Distribuição dos grupos etários (determinados por três classes) de acordo com o seu desempenho no teste de segmentação (teste 4 a)

\begin{tabular}{|c|c|c|c|c|c|}
\hline & & & \multicolumn{2}{|c|}{$\begin{array}{c}\text { Teste de soletração } \\
\text { (avaliação do } \\
\text { desempenho) }\end{array}$} & \multirow[t]{2}{*}{ Total } \\
\hline & & & $\begin{array}{l}\text { Resposta } \\
\text { incorrecta }\end{array}$ & $\begin{array}{l}\text { Resposta } \\
\text { correcta }\end{array}$ & \\
\hline \multirow{16}{*}{$\begin{array}{l}\text { Grupos } \\
\text { etários }\end{array}$} & $7-12$ & $\mathrm{~N}$ & 10 & 6 & 16 \\
\hline & & $\begin{array}{l}\% \text { nos grupos determinados por } \\
\text { idade }\end{array}$ & $62,5 \%$ & $37,5 \%$ & $100,0 \%$ \\
\hline & & \% no teste de soletração & $31,3 \%$ & $40,0 \%$ & $34,0 \%$ \\
\hline & & $\%$ Total & $21,3 \%$ & $12,8 \%$ & $34,0 \%$ \\
\hline & $13-18$ & $\mathrm{~N}$ & 8 & 8 & 16 \\
\hline & & $\begin{array}{l}\% \text { nos grupos determinados por } \\
\text { idade }\end{array}$ & $50,0 \%$ & $50,0 \%$ & $100,0 \%$ \\
\hline & & \% no teste de soletração & $25,0 \%$ & $53,3 \%$ & $34,0 \%$ \\
\hline & & $\%$ Total & $17,0 \%$ & $17,0 \%$ & $34,0 \%$ \\
\hline & $19-30$ & $\mathrm{~N}$ & 14 & 1 & 15 \\
\hline & & $\begin{array}{l}\% \text { nos grupos determinados por } \\
\text { idade }\end{array}$ & $93,3 \%$ & $6,7 \%$ & $100,0 \%$ \\
\hline & & \% no teste de soletração & $43,8 \%$ & $6,7 \%$ & $31,9 \%$ \\
\hline & & $\%$ Total & $29,8 \%$ & $2,1 \%$ & $31,9 \%$ \\
\hline & Total & $\mathrm{N}$ & 32 & 15 & 47 \\
\hline & & $\begin{array}{l}\% \text { nos grupos determinados por } \\
\text { idade }\end{array}$ & $68,1 \%$ & $31,9 \%$ & $100,0 \%$ \\
\hline & & \% no teste de soletração & $100,0 \%$ & $100,0 \%$ & $100,0 \%$ \\
\hline & & $\%$ Total & $68,1 \%$ & $31,9 \%$ & $100,0 \%$ \\
\hline
\end{tabular}

\section{Discussão de resultados}

Os resultados obtidos e sucintamente descritos na secção anterior permitem-nos identificar algumas dificuldades de descodificação e codificação de sujeitos que constituem, neste estudo, uma amostra representativa das populações discentes migrantes em Portugal. Particularmente, abordamos os testes de identificação de pares mínimos e de segmentação fonémica, ambos situados ao nível de avaliação da consciência alfabética ou fonémica. 
A identificação de pares mínimos permite ao próprio sujeito avaliar as suas competências de descodificação fonémica, ao mais alto nível da consciência fonológica, na medida em que identificar pares mínimos é prova de conhecimento da matriz fonológica da língua em que opera. Um par mínimo diz respeito a duas palavras (exemplo de [pate] e [bate]) que apenas diferem num determinado fonema, o que altera não só a fonética das palavras, como também determina os seus significados. Portanto, esse par mínimo (o exemplo) é uma prova de que os fonemas $/ p /$ e /b/ são realmente unidades distintivas (efectivamente fonemas), cujo traço distintivo assenta numa propriedade articulatória: sonoridade (para /b/ há vibração das cordas vocais, o que não ocorre na produção de /p/).

Considerando o teste apresentado, o par mínimo 'pinha' e 'pilha' foi menos identificado em comparação com o par 'cão' e 'pão'. O desempenho mais positivo em relação ao segundo par mínimo poderá estar relacionado mais fortemente com a posição das consoantes no primeiro par, ou seja, sugerimos francamente que a posição medial é mais difícil de identificar. Por outro lado, os fones a serem distinguidos nesse par constituem, com a letra "h", os dígrafos "Ih", "nh", o que mascara a identidade dos fones. Ainda, alguns locutores dominam sistemas fonológicos maternos que não têm experiência com as propriedades palatais de consoantes (sobretudo no que respeita a palatais laterais), sendo que esses traços são frequentes no português europeu e raros na maioria das línguas naturais (Freitas, 2001). Mesmo no caso dos aprendentes nativos, durante a sua alfabetização apresentam uma aquisição naturalmente tardia em relação a tais consoantes. A forma como os indivíduos identificam os pares mínimos determina a sua percepção do sistema fonético que, por sua vez, determina a própria produção articulatória (Flege, 1993).

Por outro lado, os segmentos referidos não são muito frequentes nas línguas (podem, muito provavelmente, não integrar o sistema fonético da língua materna do indivíduo), não sendo a posição o único argumento a avançar na explicação do desempenho medíocre dos sujeitos avaliados. $O$ desempenho revelado nesta tarefa apresenta-se, de forma geral, pouco positivo, sendo que as estratégias utilizadas (Flege \& Hillenbrand, 1984) pelos sujeitos podem não ser muito eficazes na detecção dos contrastes fonéticos que determinam a identidade fonémica de cada par mínimo. Os sujeitos 
parecem ser facilmente influenciados pelo obstáculo da "homopheneithy" (Binnie, Montgomery, \& Jackson, 1974), ou seja, similaridade de som (homofonia), na medida em que o sujeito é desafiado, na sua discriminação auditiva, para detectar qual a unidade distinguível no par de palavras apresentado. O conjunto de traços distintivos que, por sua vez, define o fonema poderá estar a sofrer interferência do sistema fonológico materno do indivíduo. Considera-se que as crianças primam pela atenção selectiva (Curtis \& Kruidenier, 2005); contudo, é o grupo de alunos com menos idade (menos de 9 anos) que mais erra nesta tarefa (ver tabela 1), não detectando os detalhes de traços distintivos aquando da audição dos dois pares mínimos dispostos no teste, o que vai ao encontro do argumento conclusivo de Flege, Frieda, Walley, e Randazza (1998, p. 157): "Finally, children have more difficulty than adults in discriminating minimally paired words".

O julgamento de pares mínimos é um tipo de exercício estruturalista (em termos de análise linguística dos segmentos) e que exige maior processamento ao nível de áreas do hemisfério direito, o que poderá contribuir para explicitar a performance dos sujeitos mais jovens, na medida em que é com o avanço da idade que o envolvimento do hemisfério direito na função da linguagem, sobretudo segunda, se postula como sendo mais evidente. Especificamente, o par 'pinha/pilha' ofereceu maior problema à sua identificação provavelmente porque a informação distintiva encontra-se em posição medial e não inicial (como em 'cão/pão'), logo a criança revelou menor discriminação, uma vez que, segundo Flege et al. (1998, p. 157), "children need to hear a larger portion from the beginning of words presented in a gating task in order to identify the words than do adults". Além disso, essa posição medial é 'agravada', como já referido, pela associação de duas letras (um grafema), compondo assim apenas um significado fonético ([K]) que pode ocorrer com alguma frequência, sobretudo considerando a presença da aspiração em consoantes (Repp, 1980).

As crianças (7-9 anos de idade) poderão, à semelhança do que acontece nas primeiras semanas de vida, estar a experienciar fases de menor discriminação que apenas são temporárias, seguidas por períodos de 'surto' em performance verbal. Os bilingues são mais afectados por este tipo de fases do que os monolingues, dada a exposição a dois sistemas linguísticos. Contudo, isto determina vias de aquisição diferentes, assim como estratégias 
distintas que diferenciam os sujeitos e evidenciam vantagem posterior para o bilingue.

No teste de segmentação fonémica (realizado via soletração), bem como no de leitura de um grupo de vocábulos dispostos de forma aleatória ('passagem', 'bagagem', 'vaso', 'onda'), as crianças não se destacam também como o grupo mais bem sucedido, sendo que o grupo de adolescentes (com idades compreendidas entre os 13 e os 18 anos) é o que evidencia maior sucesso na soletração de quatro palavras apresentadas. Por outro lado, são os adultos que revelam pior performance em ambos os testes. Reportandonos aos resultados dos restantes testes, percebemos que este é um dos níveis em que raramente os adultos apresentam fraca performance, posto que é este grupo etário que mais se evidencia positivamente na resolução de todos os testes da bateria. O facto de os adolescentes apresentarem uma competência articulatória mais evidenciada (Andrade \& Martins, 2007) favorecida pela maior velocidade no acto de produção, associada também à "variability in the pathways of articulation" (Andrade \& Martins, 2007, p. 778), poderá justificar o seu positivo e destacado desempenho no teste de soletração e de leitura das palavras igualmente soletradas. A sua capacidade aperfeiçoada de percepção articulatória influencia a sua performance na produção, bem como na avaliação da mesma.

O processo de segmentação, bem como outros já referidos, envolvem o sujeito ao nível fonémico, logo exigindo um conhecimento mais ou menos sólido da consciência fonológica na língua em que opera. Considerando que os adultos são encarados como sendo os aprendentes que parecem iniciar os seus processos de compreensão de palavra a partir do nível mais complexo como o da unidade mínima (fonema), neste caso tal não se verifica, especificamente na tarefa de segmentação, sendo que os adolescentes exibem mais destreza, ao passo que as crianças se situam a meio caminho, sendo contudo mais bem-sucedidas neste teste do que os colegas adultos. Estes revelam maior problema no que respeita à identificação dos sons como [g], sendo que foi observado, aquando da gravação sonora da resolução oral, que havia mais tempo despendido (provocado pelas tentativas de aperfeiçoamento articulatório para produção correcta do som) face a esse tipo de fones, quanto à sua produção e subsequente percepção. 
É notória a interferência da Língua Materna (LM) do sujeito na produção dos sons, em que a produção fonética por analogia (Gillon, 2004) se denota, parecendo, assim, haver uma tendência aprendida de reconhecimento por analogia. Há três tipos de situações que podem ocorrer na percepção do discurso em L2: assimilação a categoria fonética nativa, assimilação do fone como não categorizado (desconhecido) e, por fim, não assimilação como discurso (Aoyama, 2003). Acreditamos que seja mais frequente a primeira situação, sendo que é provável a concomitância com a negligência de sons.

É frequente que os locutores produzam e percebam sons, sobretudo as vogais, como verdadeiros alofones, em Língua Segunda, na perspectiva do fone materno. Efectivamente, consideramos bastante mais difícil para o locutor/ouvinte perceber, codificar e, assim, produzir um som que, a priori, apresente similaridade com determinado fone do seu sistema fonético materno, do que realizar um som que desconhece inteiramente, podendo iniciar o processo completo de conhecimento fonético relativo à unidade mínima implicada. Por esta razão se poderá explicar a dificuldade revelada por alunos que, embora contactem frequentemente com o Português, oriundos dos Países Africanos de Língua Oficial Portuguesa (PALOPs) ou do Brasil, manifestam dúvidas ao nível da percepção e produção de fones que constituem para eles alofones a partir dos sons que já conhecem (exemplo mais conhecido é o das vogais [e] e [o]). Assim, estes fones (alofones) podem ser neutralizados de acordo com o contexto (ou seja, deixarem de constituir

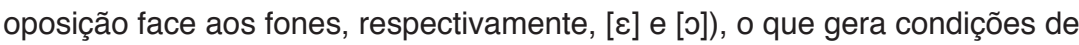
menor percepção fonémica, já que é mais dificilmente captada a oposição neutralizável do que a contrastiva, ou seja, uma oposição neutralizável não constitui uma verdadeira oposição que determine, portanto, a unidade mínima distintiva (Boomershine, Hall, Hume, \& Johnson, 2005).

A situação de oposição contrastiva subentende que um determinado fonema em determinada posição (por exemplo o fonema /R/ será sempre /R/ quando concretizado em início de palavra; contudo, não se verifica o mesmo em posição medial, que passa a ser realizado como [r]) manter-se-á sempre no mesmo segmento, sem adulterar a sua identidade. Por sua vez, o impacto da alofonia e do contraste fonémico (de que é exemplo o 'par mínimo') tem efeitos não só ao nível da percepção fonética e fonológica, mas também ao nível da semântica, concorrendo, assim, para a compreensão da palavra. 
Para efectivar a percepção do discurso e dos seus componentes não bastará conhecer individualmente cada fone, mas também relacioná-lo no seio do sistema fonológico, ou seja, detectar a sua identidade a partir do conjunto de interacções que são susceptíveis de ocorrer numa determinada língua. Daqui é possível, para o locutor, apreender as oposições neutralizáveis e as contrastivas. Na perspectiva da compreensão por analogia, esta revela-se uma estratégia que também, por si mesma, pode ser transferida da língua materna para a segunda, funcionando não só no reconhecimento de vocábulos globais como também no de unidades mínimas como o fonema. A eficácia dessa aplicação poderá, no entanto, não ser tão evidente no contexto de novo código linguístico.

À medida que a experiência com a nova língua aumenta, é natural que a discriminação também seja ajustada como se fosse recodificada. Os sujeitos, sobretudo crianças e adolescentes, evidenciaram melhor performance na tarefa de soletração (segmentação na produção) de palavras portuguesas do que no teste de identificação de letras soletradas, sem conexão entre eles e individualmente exibidos (/a/;/R/;/v/;f/). O ouvinte não nativo depara-se geralmente com problemas tais como a pseudo-homofonia e a activação de palavra espúria, baseando-se na informação do seu sistema linguístico materno. Deste modo, tem tendência a perceber os fones no contexto de determinado vocabulário, não considerando fácil a descodificação de unidades de som abstractas (ao nível do fonema) e descontextualizadas (Flege et al., 1998), como é o caso do teste de identificação de sons anteriormente enunciado. Assim, prevalece o princípio da familiaridade vocabular que supõe, por sua vez, "surrounding phonetic context" (Flege et al., 1998, p. 157).

A aprendizagem do novo sistema fonético torna-se difícil porque na primeira aprendizagem fonética o sujeito pautou-se por uma aquisição da identidade holística (Flege et al., 1998) do fone, e não de forma particularizada, sendo que, em situação de transferência para outro código, determinados traços terão de ser seleccionados e devidamente recuperados no reconhecimento do fone estrangeiro. É muito comum, portanto, a julgar pela observação dos resultados anteriores, que os aprendentes de uma nova língua tendam a perceber os sons não familiares de acordo com o inventário fonético da sua própria língua materna, sendo que as vogais são os sons mais 
filtrados (Imsri \& Idsardi, 2002; Flege, Meador, \& MacKay, 1999). Na posição dos autores que defendem os princípios do conexionismo, aplicado à área de aquisição de L2, os padrões - "linguistic pattern complexes" (Gasser, 1990, p. 12) - adquiridos na LM são transferidos para o processamento em contexto de L2:

(...) once a network has learned an association of a pattern P1 with a pattern $\mathrm{P} 2$, when it is presented with a new pattern $\mathrm{P} 3$, this will tend to activate a pattern that is similar to P2 just to the extent that P3 is similar to P1 (Gasser, 1990, p. 13).

Este tipo de princípios comprova a existência e importância dos universais linguísticos que se encontram proeminentes no desenvolvimento de linguagem e línguas ao longo da vida do ser humano. A questão permanece na forma como são adquiridos e reajustados os padrões de linguagem quando há transferência e interferência de códigos.

O sistema fonológico materno funciona como próprio filtro dos sons estrangeiros ao ouvido do locutor, sendo que este considera que no léxico estrangeiro poderá encontrar palavras cognatas, ou seja, no sentido de partilharem radicais similares a vocábulos da sua $L 1$, por, aparentemente, partilharem traços sobretudo fonéticos, o que pode não se revelar vantajoso na decisão fonética e lexical: "Cognate status has been shown to affect performance in a wide range of psycholinguistic tasks" (Flege et al., 1998, p. 159). É importante ter em conta o papel da percepção de palavras cognatas por parte dos locutores, o qual depende da organização do léxico que, de acordo com quadros teóricos relacionados com a questão, pode estar numa "common store" (Flege et al., 1998, p. 158), ou seja, as formas fonológicas são independentes mas estão ligadas a um mesmo referente (semântica), ou numa "separate store" (Flege et al., 1998, p. 158), em que as formas fonológicas estão directamente ligadas sem mediação semântica, sendo que o significado é acedido indirectamente pela forma fonológica do equivalente na LM.

A forma como o léxico influencia a capacidade particular de segmentação ao nível da produção oral continua a não estar completamente esclarecida (Flege et al., 1998). Contudo, será natural que o tipo de léxico, derivado do tipo de língua que o locutor exibe, determinará a sua capacidade de segmentação e o tipo de acento e entoação que concretiza aquando da produção fónica. 


\section{Considerações finais}

Pretendemos, com a bateria desenvolvida e com a discussão dos resultados obtidos, revelar que "o problema para alguém [na investigação científica da competência do falante] preocupado com processos operacionais" afinal já não pode consistir "em desenvolver testes que dêem resultados correctos e façam distinções relevantes" (Chomsky, 1978, p. 101). O nosso objectivo é identificar pistas de desempenho e intuição dos sujeitos para poder contribuir futuramente com um teste que se apresente como oportunidade de nivelar o desempenho dos sujeitos e informá-los sobre a situação da sua competência, sem catalogar "resultados correctos".

Naturalmente, os aprendentes de Língua Segunda surgem como alunos de risco no que respeita ao desenvolvimento das competências literácitas (Snow, Burns, \& Griffin 1998), determinando o desempenho académico geral. Deste modo, a bateria de testes desenvolvida para esta investigação é um contributo para a educação, na medida em que se assevera como um instrumento importante de avaliação diagnóstica e, simultaneamente, enquanto programa de intervenção no ensino e aprendizagem, dirigido especificamente a alunos que estejam a iniciar o processo de aprendizagem/aquisição de Português Língua Segunda, podendo fornecer indicadores que facilitam ao professor/educador o processo de atribuição de níveis de proficiência (Comissão Europeia, 2001) de acordo com a performance que os alunos revelem. Por outro lado, determina mais eficazmente em que níveis da Língua o sujeito revela maior competência, deduzida pelo seu desempenho que, de forma célere, é captado pelo teste electrónico.

A configuração do teste é pautada pelo princípio da organização de níveis de tarefas, pela precisão e controlo na audição dos estímulos sonoros e em situação de tarefas de escrita condicionada, como também pelo dinamismo proporcionado na interacção do utilizador com os estímulos apresentados no teste e pela capacidade de controlo e registo do tempo despendido pelo sujeito em cada tarefa. A aplicação do teste permite traçar o perfil dos comportamentos verbais, escritos ou orais dos alunos, contribuindo, assim, para a programação de actividades de aprendizagem, fomentando um percurso escolar com sucesso, em que o conhecimento da língua é fundamental. 


\section{Referências}

Andrade, C., \& Martins, V. (2007). Fluency variation in adolescents. Clinical Linguistics \& Phonetics, 21(10), 771-782.

Aoyama, K. (2003). Perception of syllable-initial and syllable final nasals in English by korean and japanese speakers. Second Language Research, 19(3), 251-265.

Bassetti, B. (2005). Learning second language writing systems. Disponível em http://www.llas.ac.uk/resources/goodpractice. aspx?resourceid=2662 (acesso em 6 de Junho de 2007).

Binnie, C. A., Montgomery, A. A., \& Jackson, P.L. (1974). Auditory and visual contributions to the perception of consonants. Journal of Speech and Hearing Research, 17, 619-630.

Boomershine, A., Hall, K., Hume, E., \& Johnson, K. (2005). The impact of allophony versus contrast on speech perception. Disponível em http://linguistics.berkeley.edu/ kjohnson/papers/Boomershine_et_al_2005.pdf (acesso em 18 de Junho de 2007).

Bosch, L., \& Sebastián-Gallés, N. (2003). Simultaneous bilingualism and the perception of a language-specific vowel contrast in the first year of life. Language and Speech, 46(2-3), 217-243.

Bruck, M., \& Genesee, F. (1995). Phonological awareness in young 2nd language learners. Journal of Child Language, 22(2), 307-324.

Chomsky, N. (1978). Aspectos da teoria da sintaxe ( $2^{\mathrm{a}}$ ed.). Coimbra: Arménio Amado.

Comissão Europeia, Conselho da Europa (2001). Quadro Europeu Comum de Referência para as Línguas - Aprendizagem, ensino, avaliação. Porto: Edições Asa.

Curtis, M. E., \& Kruidenier, J. R. (2005). A summary of scientifically based research principles: Teaching adults to read. Disponivel em http://www.nifl.gov/ partnershipforreading/publications/html/teach_adults/teach_adults.html (acesso em 29 de Maio de 2007).

Flege, J. (1993). Production and perception of a novel, second-language phonetic contrast. Acoustical Society of America Journal, 93(3), 1589-608.

Flege, J., Frieda, E., Walley, A., \& Randazza, L. (1998). Lexical factors and segmental accuracy in second language speech production. Studies in Second Language Acquisition, 20, 155-187.

Flege, J. E., \& Hillenbrand, J. (1984). Limits on phonetic accuracy in foreign language speech production. Acoustical Society of America Journal, 76(3), 708-721.

Flege, J., Meador, I. R., \& Mackay, D. (1999). Native Italian speakers' perception and production of English vowels. Acoustical Society of America Journal, 10, 297387.

Floccia, C., Nazzi, T., Austin, K., Arreckx, F., \& Goslin, J. (2010). Lexical stress and phonetic processing in word learning in 20- to 24-month-old English-learning children. Developmental Science, 1-12.

Freitas, M. J. (2001). Os pontos nos seus lugares: Considerações sobre as laterais na aquisição do Português Europeu. In Razões e emoções. Miscelânea de estudos 
oferecida a Maria Helena Mateus. Lisboa: Faculdade de Letras da Universidade de Lisboa - Departamento de Linguística Geral e Românica.

Gasser, M. (1990). Connectionism and universals of second language acquisition. Studies in Second Language Acquisition, 12, 179-199.

Imsri, P., \& Idsardi, W. (2002). The perception of stops by Thai children and adults. Disponível em ISCAArchive database (acesso em 1 de Fevereiro de 2007).

Jusczyk, P. W. (1994). Infant speech perception and the development of the mental lexicon. In J. Goodman \& H. Nusbaum, The development of speech perception: The transition from speech sounds to spoken words (pp. 227-270). Cambridge, MA: MIT Press.

Jusczyk, P. W., \& Bertoncini, J. (1988). Viewing the development of speech perception as an innately guided learning process. Language and Speech, 31(3), 217-238.

Leiria, I. (1999). Português língua segunda e língua estrangeira: Investigação e ensino. Disponível em http://www.aulaintercultural.org/article.php3?id_article=1642 (acesso em 25 de Agosto de 2008).

Lenneberg, E. H. (1967). Biological foundations of language. New York: John Wiley.

Ministério da Educação (2005). Português língua não materna no currículo nacional. Direcção-Geral de Inovação e Desenvolvimento Curricular. Disponível em http://www.dgidc.min-edu.pt/plnmaterna/DN7/PLNMDoc_orientador.pdf

Postman, N., \& Weingartner, C. (1971). Contestação - Nova fórmula de ensino. RJ: Expressão e Cultura.

Schütz, R. (2005). Os fonemas vogais do Inglês e do Português. Disponível em www.sk.com.br/sk-voga.html (acesso em 17 de Março de 2008).

Skinner, B. F. (1978). O comportamento verbal como uma variável dependente. In B. F. Skinner, Comportamento verbal (pp. 29-52). São Paulo: Cultrix Editor.

Snow, C., Burns, S., \& Griffin, P. (Eds.). (1998). Preventing reading difficulties in young children. Washington: National Academy Press.

Ziegler, J. C., Jacobs, A. M., \& Braun, M. (2001). Identical words are read differently in different languages. Psychological Science Journal, 12(5), 379-84. 


\title{
INTERVENTION PROGRAMME IN AN EDUCATIVE CONTEXT: ELECTRONIC DEVICE TO ASSESS PHONETIC DECODING OF PORTUGUESE AS A SECOND LANGUAGE LEARNERS
}

\begin{abstract}
The verbal behaviour is achieved because, on the one hand, there is a system of principles and conditions, which are considered as universals for all the human languages, supported by the biological need, but, on the other hand, those elements are part of the dynamic relation of events which constitutes the individual's context. Those events are not only the brain structures (mentalist perspective), but also the elements that generate the stimuli context to be discriminated which must be called 'environment' (functional perspective). After a theoretical revision of concepts and a perspective about phonetic decoding processes, results obtained by the set of tests developed for this study will be reported. Moreover some discussion will focus specifically on the achievement of second language learners regarding the segmentation (spelling task) and minimal pairs judgment tests.
\end{abstract}

Keywords

Educative intervention; Assessment instrument; Phonetic perception; Second Language

PROGRAM DE L'ACTION DANS LE DOMAINE DE L'ÉDUCATION: DISPOSITIF

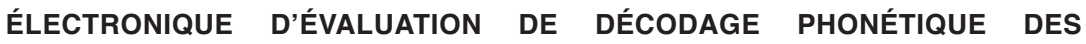
APPRENANTS DE PORTUGAISE LANGUE SECOND

\section{Résumé}

Le comportement verbal est réalisé car, d'une part, il existe un système de principes et de conditions, qui sont considérés comme les éléments universelles inhérent à toutes les langues naturelles, tel que déterminé par la nécessité biologique, mais d'autre part, ces éléments comprennent une 
relation dynamique des événements qui constituent le cadre de le sujet. Dans ce contexte, ces événements ne sont pas seulement les structures du cerveau (perspective mentaliste), mais tous les éléments qui génèrent un contexte de stimuli qui doit être discriminé, à qui il demande de 'l'environnement' (perspective fonctionnel). Après un bref examen théorique des concepts et les procédures d'approche pour le décodage phonétique, seront présentés les résultats de la application de la batterie de tests (instrument de recherche). II sera aussi un débat a porté spécifiquement sur les capacités de sujets apprenants de langue second (échantillon de l'étude) dans les tests de la segmentation et l'identification de paires minimales.

Mots-clé

L'intervention éducative; Instrument d'évaluation; Perception phonétique; Langue Second

Recebido em Maio/2011

Aceite para publicação em Janeiro/2012

Toda a correspondência relativa a este artigo deve ser enviada para: Sandra Figueiredo, Departamento de Ciências da Educação, Universidade de Aveiro, Campus Universitário Santiago, Edifício 18, 3810-193 Aveiro, Portugal. E-mail: sandradfigueiredo@ua.pt 